\title{
Maternal Response of Perinatally Underfed Wistar Virgin Females Exposed to Newborn Rats
}

\author{
Manuel Salas, Mirelta Regalado, Carmen Torrero, Minerva Ortiz-Valladares, Lorena Rubio \\ Department of Developmental Neurobiology and Neurophysiology, Institute of Neurobiology, National Autonomous University \\ of Mexico, Campus UNAM Juriquilla, Queretaro, Mexico
}

Email: masal@unam.mx

How to cite this paper: Salas, M., Regalado, M., Torrero, C., Ortiz-Valladares, M. and Rubio, L. (2019) Maternal Response of Perinatally Underfed Wistar Virgin Females Exposed to Newborn Rats. Journal of Behavioral and Brain Science, 9, 78-89. https://doi.org/10.4236/jbbs.2019.93007

Received: February 6, 2019

Accepted: March 1, 2019

Published: March 4, 2019

Copyright $\odot 2019$ by author(s) and Scientific Research Publishing Inc. This work is licensed under the Creative Commons Attribution International License (CC BY 4.0).

http://creativecommons.org/licenses/by/4.0/

(c) (i) Open Access

\begin{abstract}
Nutrition plays a major role in the survival of the progeny, and its perinatal deficiencies delay physical development and interfere with social and cognitive performance later in life. The effects of early undernutrition on maternal social performance of sensitized adult virgin rats were evaluated. Several maternal and non-maternal responses were measured in virgin female Wistar rats randomly divided into two groups, control and early undernourished, during 19 days of chronic daily exposure to fresh foster pups in home-cage conditions. Underfed females (F0) received different percentages of a balanced diet during gestation. After birth, pups were underfed (F1) by alternating every $12 \mathrm{~h}$ between litters two lactating dams, one with ligated nipples. Weaning was at 25 days of age followed by an ad lib diet until postpartum day 90, when sensitized virgins were maternally tested daily for seven successive sessions. Significantly $(\mathrm{p}<0.05)$ low body weight scores in UG F1 virgins of five different ages were observed. The UG F1 females expressed significantly ( $\mathrm{p}<0.05)$ lower frequency values in sniffing, licking, retrieving, crouching, and handling shavings, with clear prolonged sniffing, retrieving and handling shaving latencies towards the foster pups compared with CG F1 sensitized females. Self-grooming was not affected, whereas exploration was significantly reduced. Current findings suggest that perinatal undernutrition interfered the organization of a core neuronal circuitry underlying the mother-litter interactions involved in social and cognitive performance of sensitized adult virgins. Furthermore, the behavioral maternal alterations in F1 virgins may possibly generate a risky negative social environment to induce cognitive and/or brain disorders in later generations.
\end{abstract}

\section{Keywords}

Early Undernutrition, Maternal Sensitization, Cognitive Development, Rats 


\section{Introduction}

Several studies have shown that different paradigms of perinatal undernutrition or early malnutrition in the rat result in long-term maternal response deficiencies, which interfere with the physical and functional growth of the young and include significant alterations in nest building, pup licking, kyphotic posture for nursing, and retrieval of the newborn [1]. These long-term behavioral alterations may result in interference with the programming of the hypothalamic-hypophysealadrenal axis (HPA), which results in metabolic and defects of activating hormonal targets to trigger adaptive responses including the maternal response [2]. Furthermore, these alterations are correlated with disrupted neuronal integration due to the loss of neurons and reduced dendritic arbors, spines and perikarya in sensory systems that are associated with early food restriction as a stressor that interferes with mother-litter bonds, resulting in cognitive functional deficiencies and brain disorders throughout the lifespan of the progeny [3]. In mammals the mother-litter interactions are widely integrated in an ancient and complex neuronal circuit that guarantees maternal care to the pups and promotes their survival in nature. Infants, adolescents and adult males and females are equipped with these maternal circuits in their brains; however, they may be quiescent and waiting for the proper hormonal and environmental stimulation to initiate complex mechanisms to provide care for the survival and protection of the progeny [4]. Pregnant dams have the brain capacities for reorganization and the functional conditions necessary to provide adequate attention to their young. Furthermore, the daily chronic exposure of adult virgin females to newborn pups results in a gradual appearance (sensitization) of several maternal behavior components to care for the immature newborns [5]. These females do not need to be pregnant or lactating to be maternally motivated [6].

In recent years, it has been shown that in poor and underdeveloped countries the frequency of pregnant and underfed teenagers has increased as a serious multifactorial social problem because the adolescent mothers are themselves growing, competing with their own fetuses or newborns for food, and lack access to social facilities and medical assistance. In adolescent dams, the deficient maternal experience calls for help and care of nonmaternal foster mothers, or the aid of other family members who are not prepared to give the adequate love and maternal care; therefore, the progeny may exhibit deficits in the long term, but these remain unclear [7] [8]. For these reasons, it is necessary to investigate if the progeny of early underfed pregnant females is substantially prone to having long-term maternal cognitive disorders.

To our knowledge, there is a lack of information on whether early underfed adult virgin female rats could initially be sensitized and characterized by the daily exposure to foster pups compared with normally feeding virgin females. Thus, the current study analyzed how the maternal behavior components of control or perinatally underfed adult virgin females were expressed, and if the mother-litter interactions in this experimental model may have negative consequences for the later physiological development of newborns that may further on investigated. 


\section{Materials and Methods}

\subsection{Animals and Experimental Design}

Subjects were adult virgin female Wistar rats of 90 days of age (200 - $250 \mathrm{~g})$, descendants of a stock obtained from Harlan Sprague Dawley (IN, USA). The rats were maintained in an automatically controlled room at $23^{\circ} \mathrm{C} \pm 2{ }^{\circ} \mathrm{C}$ and $50 \%$ humidity on a 12:12 h day/night cycle (lights on at $07: 00 \mathrm{~h}$ ), with water and food (5001, rodent Purina chow) ad lib. For mating, two males of 90 - 120 days of age (350 - $400 \mathrm{~g}$ ) were placed in a $60 \times 40 \times 20 \mathrm{~cm}^{3}$ clear Plexiglas cage containing four virgin females as above mentioned. Sperm-positive females were placed in maternity cages $\left(50 \times 40 \times 20 \mathrm{~cm}^{3}\right)$ with grill tops and coarse sawdust for bedding. The day after delivery was defined as postnatal day (PD) 1 . Within $24 \mathrm{~h}$ after birth, pups were randomly mixed, weighed and sexed, so that each litter consisted of ten pups (five females and five males) to minimize genetic and nutritional differences that could influence the experimental results. Experimental procedures were carried out in agreement with the Guidelines of the National Research Council for Care and Use of Animals [9], and with Official Mexican Standard NOM-062-ZOO-1999. All efforts were made to reduce the number of animals used and their suffering.

\subsection{Nutritional Treatment}

\subsubsection{Control Group (CG)}

The CG consisted of 12 female pups obtained from five litters normally fed by well-fed mothers that had free access to food (5001 rodent Purina chow) and water during gestation and lactation periods. After birth, pups were fed and handled by interchanging a pair of sham nipple-ligated control mothers every 12 $\mathrm{h}$ for (at 08:00 and 20:00 h) 24 days as described elsewhere [10]. This paradigm allows the dam to adequately nurse and care for the pups (body licking, olfactory searching, posture over the pups and retrieving). The virgin F1 female rats obtained by following this procedure ( $\mathrm{n}=10$ females) were exposed daily to a constant number of six young ( 3 females and 3 males) fresh pups through the daily mating of as many donor rats, and then F1 rats were maternally tested at PD 90 (Figure 1(A)).

\subsubsection{Undernourished Group (UG)}

The UG consisted of 12 F0 females that came from five different litters. The normal chow diet requirement was calculated by measuring the food intake of a group of 6 pregnant control rats $(200-250 \mathrm{~g})$ every week during a 21-day period. The resulting average food intake for each week was the basal level used to calculate the food-intake percentage of the UG females. Thus, dams were fed from gestational day 6 (G6) to G12 with 50\% (9.5 g) of the normal diet (Purina chow), from G13 to G19 with 70\% (13.3 g), and with 100\% (19 g) of the same diet until parturition to avoid reabsorption or cannibalism of pups. This protocol was chosen because neurogenesis in the cortical and subcortical maternal circuit 


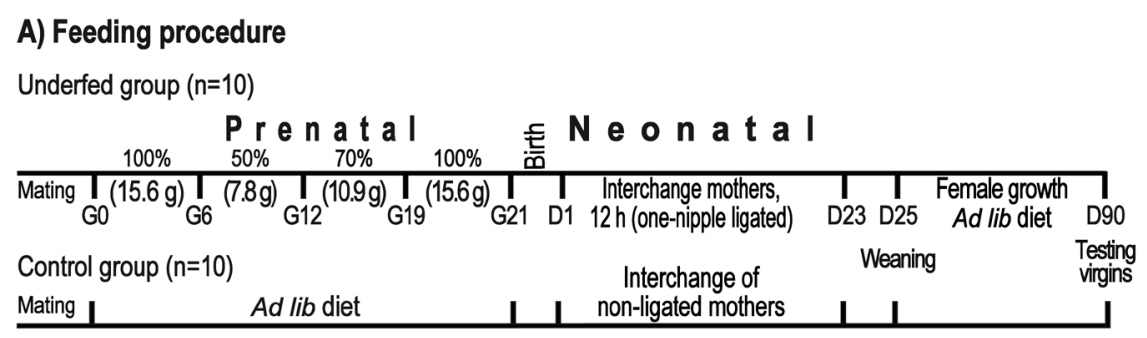

\section{B) Maternal sensitization and video recording:}

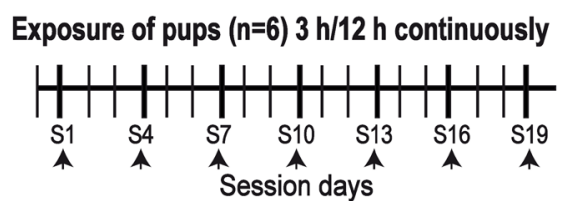

Figure 1. (A) Schematic representation of the feeding procedure of experimental groups. (B) Paradigm of maternal sensitization of CG and UG virgin females, and behavioral recording procedure (15 $\mathrm{min})$ throughout each session.

and afferent connectivity occur mainly from G16 to G21 [11]. At birth, prenatally underfed female young were fed by two gestationally underfed dams, in one of which the main galactophorous ducts had been tied subcutaneously under surgical anesthesia. The two lactating dams were interchanged every $12 \mathrm{~h}$ between litters from PDs 1 to 24. Weaning was performed on PD 25, after which the rats were allowed free access to water and food (Purina chow). F1 females $(\mathrm{n}=10)$ were maintained in groups of 4 to 6 until PD 90, when they were maternally sensitized by the chronic exposure to pups and tested for maternal behavior in their home-cage with six pups (3 females and 3 males) between $1-7$ days of age (Figure $1(B)$ ). No attempts were made to measure food intake in F0 pregnant dams or F1 newborn female rats. Approximately $80 \%$ of the total underfed virgin females in this experiment were undernourished during the light phase of the cycle.

\subsection{Behavioral Testing}

In all cases the protocol for maternal sensitization of CG or UG virgin females living with foster pups was the same. Before the exposure to pups, virgin females were placed for two consecutive days in translucent individual home maternity testing cages $\left(35 \times 27 \times 17 \mathrm{~cm}^{3}\right)$ for an adaptation period of $3 \mathrm{~min}$. After this period half a litter (6 recently fed newborn rats of both sexes), provided by a donor control mother, were scattered in the center of the observation cage for $3 \mathrm{~h}$ to induce maternal behavior; thereafter, the other half of the litter continued to be exposed to the virgin female for another $3 \mathrm{~h}$. This procedure was repeated 4 times a day (from 07:00 to 19:00 h) for 19 days of sensitization. To avoid pup undernutrition or dehydration, the foster pups of similar ages were taken from 10 normally fed donor mothers. After each daily $3 \mathrm{~h}$ exposure, the 6 pups of a litter were returned to their donor lactating mother for $3 \mathrm{~h}$ to avoid undernutrition and declining lactation in the dam. The maternal behavior of the experimental 
virgins from this period was video recorded from 08:00-12:00 $\mathrm{h}$ for a $15 \mathrm{~min}$ span, only on session days (SDs) 1, 4, 7, 10, 13, 16, and 19 of the experiment. This procedure of pup exposure provided a constant level of multi-sensorial stimulation directed toward the virgin females for sensitization (Figure 1(B)). To evaluate the effects of the nutritional treatments on physical development of F1 CG and UG virgin females, body weights were noted on PDs 10, 20, 30, 90 and 109.

\subsubsection{Maternal Responses}

Maternal behavior components directed toward the pups were scored over 7 days of exposure to pups and included the following frequency measurements: Approaching, defined as the frequency with which females touch a pup's body with their muzzle. Sniffing, the frequency of female approaches toward the pups with sniffing motions directed or oriented away from the young. Licking, number of maternal licking bouts directed toward the pups. Retrieving, number of times the female retrieves a pup by a body area. Crouching, the number of times the female maintains a quiescent posture with partially arched back and most of the limbs extended over the pups. Handling shavings, number of attempts to move wood shavings to build a nest. Furthermore, to analyze the temporal course of the different maternal behavior components following the exposure of the virgins to the pups, the latencies throughout the seven session days were noted.

The criteria to design a maternal virgin female were the retrieval of at least four pups to the nest or adopting a crouching posture over the pups for three consecutive days.

\subsubsection{Non-Maternal Responses}

These components were the frequency of self-grooming bouts including fore-paw licking, face washing, head rubbing, fur and genital licking, and body scratching of the virgin rat; and exploration, the number of times the female stood on her hind legs exploring the pups.

For the behavioral assessment of each dam, we assigned a random number to ensure that behavioral measurements taken by an observer were blind with respect to age and treatment, and to the hypothesis of the experiment.

\subsection{Statistics}

Body weight differences between dietary treatments and pup ages were compared by a two-way ANOVA, 2 (nutritional regimes) $\times 5$ (10, 20, 30, 90 and 109 ages) was used. The frequency and latencies of each maternal component (approaching, sniffing, licking, and retrieving pups) were analyzed with a two-way repeated measure ANOVA, 2 (nutritional regimes) $\times 7$ (SDs). Analysis of crouching and handling shavings of virgin females were compared with a two-way ANOVA, 2 (nutritional regimes) $\times 7$ (SDs). The frequencies of non-maternal self-grooming and exploration were compared with a two-way repeated measure ANOVA, 2 (nutritional regimes) $\times 7$ (SDs). Post hoc comparisons of scores between nutritional regimes over session days were made using the Fisher LSD 
post hoc test. Statistical significance was set at $\mathrm{p}<0.05$.

\section{Results}

\subsection{Development of Body Weight of CG and UG Sensitized Females}

The ANOVA of body weight scores indicated lower significant diet effects, $\left(\mathrm{F}_{1,18}=236.05, \mathrm{p}<0.0001\right)$, age, $\left(\mathrm{F}_{4,72}=3291.45, \mathrm{p}<0.0001\right)$; and a diet $\times$ age interaction, $\left(\mathrm{F}_{4,72}=18.47, \mathrm{p}<0.0001\right)$.

\subsection{Effects on the Frequency of Maternal Behavior}

Early undernutrition interfered with the frequency of sniffing, licking, retrieving, crouching, and handling shavings of the virgin females along seven SDs.

The approaching comparisons were not affected in UG virgins, $\left(\mathrm{F}_{1,18}=0.01\right.$, $\mathrm{p}<0.89)$, but they were significantly lower by $\mathrm{SD},\left(\mathrm{F}_{6,108}=6.25, \mathrm{p}<0.0001\right)$; and a SDs $\times$ diet interaction, $\left(\mathrm{F}_{6,108}=8.30, \mathrm{p}<0.0001\right)$. Post hoc comparisons of the approaching showed lower values $(\mathrm{p}<0.05)$ in the UG virgins on SD 4 and higher values on SDs 13 and 19 (Figure 2(A)). Pups sniffing showed lower values in the UG virgins, $\left(\mathrm{F}_{1,18}=98.37, \mathrm{p}<0.0001\right)$; SDs, $\left(\mathrm{F}_{6,108}=3.37, \mathrm{p}<0.004\right)$; and a SDs $\times$ diet interaction, $\left(\mathrm{F}_{6,108}=2.93, \mathrm{p}<0.01\right)$. Post hoc comparisons of the sniffing indicated significant reductions $(\mathrm{p}<0.05)$ in UG virgins on SDs 4 to 19 (Figure 2(B)). Comparisons of pup licking values were reduced in the UG virgins, $\left(\mathrm{F}_{1,18}=75.22, \mathrm{p}<0.0001\right)$; SDs, $\left(\mathrm{F}_{6,108}=7.87, \mathrm{p}<0.0001\right)$; and SDs $\times$ diet interaction, $\left(\mathrm{F}_{6,108}=4.58, \mathrm{p}<0.0003\right)$. Post hoc comparisons of licking showed significant reductions $(\mathrm{p}<0.05)$ in UG virgin rats on SD 4 and from SDs 10 to
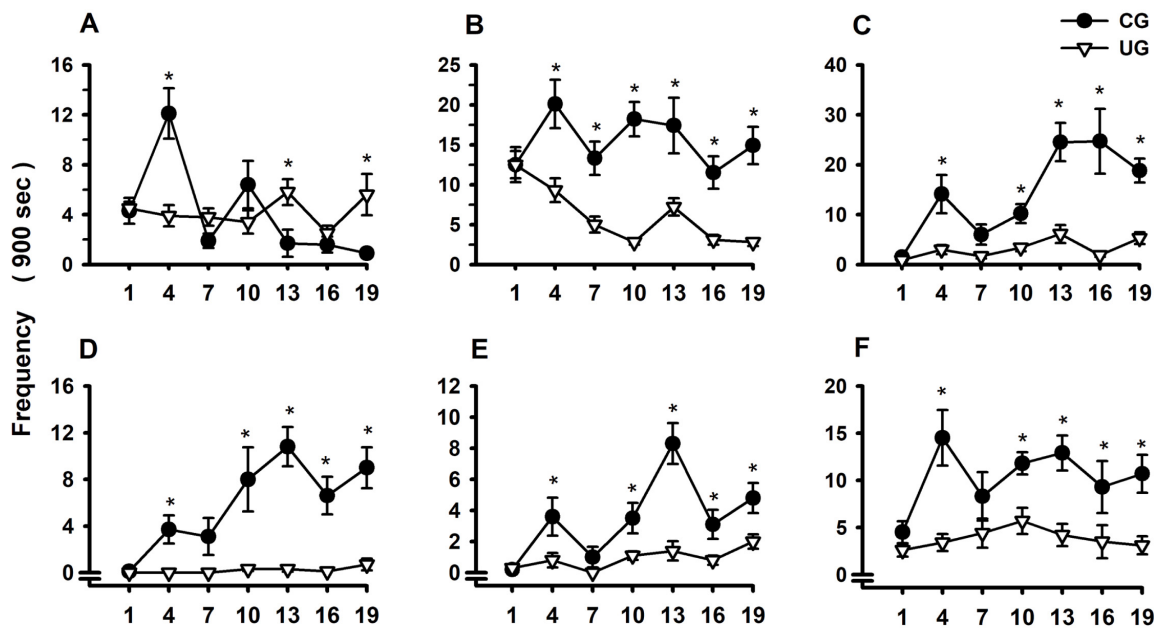

Recording session (days)

Figure 2. Frequency of sensitized behavioral components. Mean \pm SEM of frequency values in 900 seconds of (A) approaching; (B) sniffing; (C) licking; (D) retrieving; (E) crouching over pups and (F) handling shavings in the CG and UG sensitized virgins. Note in most of the maternal responses that UG F1 virgins showed significantly lower scores than CG F1 females. ${ }^{\star}$ Significant differences between experimental groups, p < 0.05. Fisher LSD test. 
19 (Figure $2(\mathrm{C}))$. The retrieval was reduced in UG virgins, $\left(\mathrm{F}_{1,18}=79.57, \mathrm{p}<\right.$ 0.0001); SDs, $\left(\mathrm{F}_{6,108}=5.34, \mathrm{p}<0.0001\right)$; and significant $\mathrm{SDs} \times$ diet interaction, $\left(\mathrm{F}_{6,108}=4.35, \mathrm{p}<0.0005\right)$. Post hoc comparisons of retrieval indicated lower values $(\mathrm{p}<0.05)$ in the UG virgins on SD 4 and from SDs 10 to 19 (Figure 2(D)). The crouching comparisons showed lower values in UG virgins, $\left(\mathrm{F}_{1,18}=33.85\right.$, $\mathrm{p}<0.0001)$, SDs, $\left(\mathrm{F}_{6,108}=9.94, \mathrm{p}<0.001\right)$; and SDs $\times$ diet interaction, $\left(\mathrm{F}_{6,108}=\right.$ $4.66, \mathrm{p}<0.0002)$. Post hoc comparisons yielded significant reductions $(\mathrm{p}<0.05)$ in UG virgins on SDs 4 and from SDs 10 to 19 (Figure 2(E)). The handling shaving indicated lower values in UG virgins, $\left(\mathrm{F}_{1,18}=51.55, \mathrm{p}<0.0001\right)$, SDs, $\left(\mathrm{F}_{6,108}=2.27, \mathrm{p}<0.04\right)$; and no interaction between factors. Post hoc comparisons of handling shavings showed low significant values $(\mathrm{p}<0.05)$ on SD 4 and from SDs 10 to 19 (Figure 2(F)). Thus, in most of these measurements the UG F1 virgins showed deficient maternal responses when compared with the CG F1 females (Figure 2).

\subsection{Effects on the Frequency of Non-Maternal Responses}

Comparisons of self-grooming between UG and CG virgins were not significantly different. However, the exploratory response was significantly lower in UG virgins, $\left(\mathrm{F}_{1,18}=28.66, \mathrm{p}<0.0004\right), \mathrm{SDs},\left(\mathrm{F}_{6,108}=6.10, \mathrm{p}<0.0001\right)$; without interaction between factors.

\subsection{Effects on the Latencies for Behavioral Appearance}

Approaching comparisons yielded short significant values in UG virgins, $\left(\mathrm{F}_{1,18}=\right.$ $16.20, \mathrm{p}<0.0007)$, without differences on SDs; and no interaction between factors. Post hoc comparisons showed significantly $(\mathrm{p}<0.05)$ lower values on SDs 13 and 19 (Figure 3(A)). The sniffing comparisons showed prolonged values in the UG virgins, $\left(\mathrm{F}_{1,18}=5.59, \mathrm{p}<0.02\right)$, effects on SDs; and no interaction between factors. Post hoc comparisons showed prolonged values in the UG virgins $(\mathrm{p}<0.05)$ on SDs 1 to 19 (Figure 3(B)). Pup licking comparisons in the UG virgins showed prolonged values, $\left(\mathrm{F}_{1,18}=5.07, \mathrm{p}<0.03\right)$; $\mathrm{SDs},\left(\mathrm{F}_{6,108}=5.83, \mathrm{p}<\right.$ $0.0001)$; and SDs $\times$ diet interaction, $\left(\mathrm{F}_{6,108}=2.38, \mathrm{p}<0.03\right)$. Post hoc comparisons indicated prolonged latency only on SD 1 (Figure $3(\mathrm{C})$ ). The retrieval comparisons were prolonged in the UG virgins, $\left(\mathrm{F}_{1,18}=53.99, \mathrm{p}<0.0001\right)$, SDs, $\left(\mathrm{F}_{6,108}=6.32, \mathrm{p}<0.0001\right)$; and SDs $\times$ diet interaction, $\left(\mathrm{F}_{6,108}=3.09, \mathrm{p}<0.007\right)$. Post hoc analysis showed prolonged values $(\mathrm{p}<0.05)$ on SD 4 and from SDs 10 to 19 (Figure 3(D)). Crouching comparisons indicated non-significant differences according to diet and significant differences according to SDs, $\left(\mathrm{F}_{6,108}=\right.$ $11.33, \mathrm{p}<0.0001)$; with no interaction between factors. Post hoc comparisons were not statistically significant (Figure $3(\mathrm{E})$ ). Comparisons of handling shavings were reduced in UG virgins, $\left(\mathrm{F}_{1,18}=22.44, \mathrm{p}<0.0001\right)$, no effects on SDs and without interaction. Post hoc analysis indicated prolonged latencies on SDs 4, 7, 16 and 19 (Figure 3(F)). In summary, less consistent prolonged latencies were observed in the UG F1 virgins compared with the CG F1 females (Figure 3). 


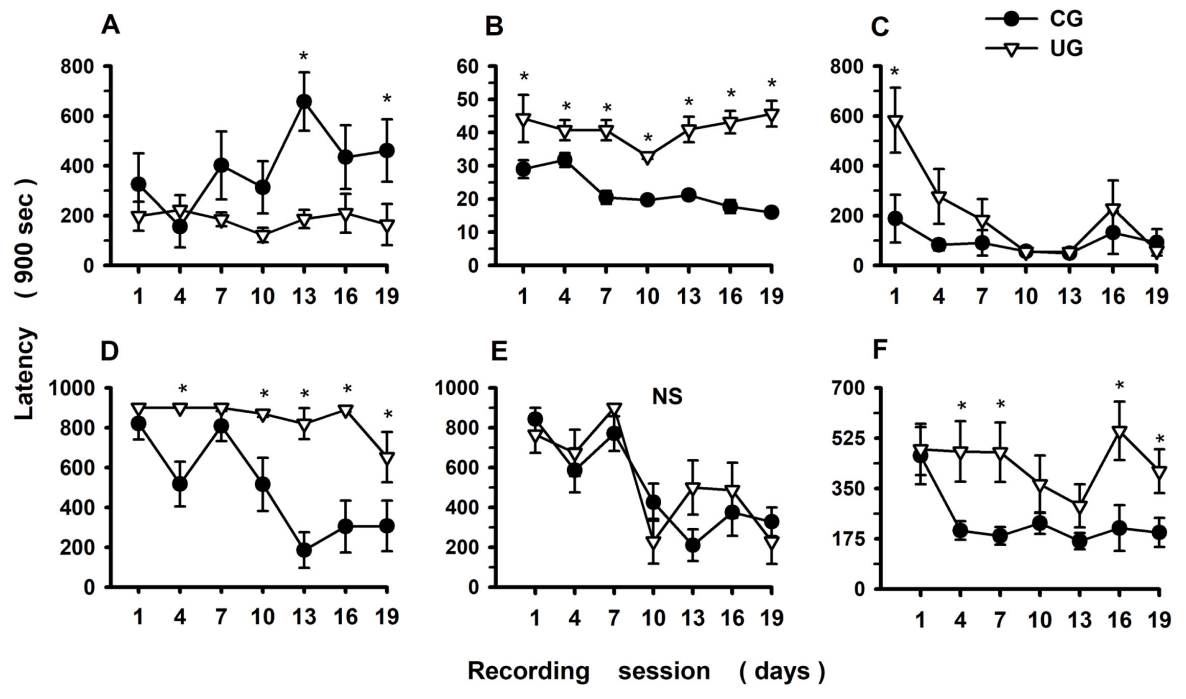

Figure 3. Latency of sensitized behavioral components. Mean \pm SEM of latency scores of maternal components elicited in the CG and UG virgin females by chronic exposure to pups as in Figure 2. Note that only consistent, significantly prolonged latencies in UG F1 females in (B), (D), and (F) were observed. ${ }^{*}$ Significant differences between experimental groups, $\mathrm{p}<0.05$. Fisher LSD test.

\section{Discussion and Conclusion}

The underfeeding paradigm established in F0 dams during gestation involved $50 \%$ to $70 \%$ of food restriction, which possibly affected the placental weight and functions and caused deficiencies in fetal nutrition and in the growth of the embryo or fetus as described elsewhere [12] [13]. From PDs 1 to 24, F1 underfed pups spent $12 \mathrm{~h}$ with a nipple-ligated dam and $12 \mathrm{~h}$ with a normally lactating mother, where they received maternal sensory stimulation in the encounter that ameliorated their low body weight and/or reduced food consumption [14] [15]. Thereafter, UG F1 virgins slightly increased food consumption and body weight through a balanced diet from PDs 25 to 90; however, they were unable to compensate the low body weight provoked by early undernutrition, which was associated with their maternal deficiencies and disrupted bonding interactions with the foster pups [16].

Current data confirmed that undernutrition during gestation and suckling reduced the frequency of most of the F1 virgin female maternal components here obtained triggered by visual, olfactory and somatosensory cues elicited by fresh foster pups, except the inconsistent approach of sensitized UG females to pups compared to CG virgin females, who gradually increased their frequency of approach. Additionally, the latencies for the appearance of sniffing, retrieval, and handling shavings were significantly prolonged in F1 UG virgins in comparison with F1 CG females, with less consistent effects on approaching and crouching. In this regard, F1 UG virgins did not meet the criteria to be considered as maternally sensitized females compared with F1 CG virgins because the consistent delayed sensorial maturation associated with early undernutrition as previously 
described [17] [18]. Additionally, the long-term altered maternal components shown by UG sensitized virgins may have also other explanations. Different paradigms of malnutrition or perinatal undernutrition have shown that mother-litter bonds were severely affected when F1 pups and/or F0 dams were separated because of experimental underfeeding maneuvers [19]. Current results showed that F1 UG sensitized virgins were unable to express the maternal responses to multisensory cues elicited by normally fed newborns, because they interfered with the activation of specific maternal brain circuits with different levels of excitability to trigger efficient caretaking responses and satisfy the demands of the progeny as shown by similar pups' experimental maneuvers [20] [21]. Thus, our findings provide evidence that the deficient capabilities of UG sensitized virgins to interact and recognize olfactory, auditory, visual or tactile stimuli elicited by the pups evoked deficient female motivation, maternal care or reduced neuronal c-Fos immunostaining in the basolateral and central amygdala as previously described in early underfed or sensitized females [1] [8] [17] [21] [22]. These deficient capabilities of UG virgins had insubstantial effects on non-maternal responses. Additionally, perinatal undernutrition elicited incomplete long-term deficiencies in the maternal behavior of UG sensitized virgins, despite the daily prolonged exposure to fresh foster pups, such as the behavior exhibited by early underfed lactating dams including lower sniffing, body licking, abnormal retrieval of pups, reduced crouching and body contact, abnormal kyphotic posture and nest building deficiencies to protect the litter [1] [21] [23] [24]. Mother-litter interactions are normally established during a critical window of brain development of the young and during the first week of life, when the mother's brain circuits are changing. These facts support the possibility that early undernutrition may disrupt the concurrence of these specific neuroendocrine and social sensory mechanisms, causing long-term deficiencies in mother-infant bonding recognition [25] [26].

Another point of interest concerns the role of the neonatal underfeeding paradigm as a stressor that affects anatomical and behavioral mother-infant interactions by increasing the release of glucocorticoid, which reprograms the HPA axis of the newborn to present non-adaptive behavioral responses later in life. However, it is known that during the first 7 days of a rat's life there is a period of low or no response to hypothermia or brief periods of maternal separation that are attenuated by maternal care [27]. Thus, the daily brief separation ( $2 \mathrm{~min})$ of pups from their mothers when rats were gently rotating between litters did not affect the body and brain weight of pups, but it may have inconsistently increased the F1 virgins' manipulation or handling of pups, which possibly ameliorated brain alterations when reunited with the dam [14] [28]. After this initial period, the $12 \mathrm{~h}$ interchanging of F0 dams between F1 litters for a 2 min span from PDs 8 - 24 may suggest an interference with the reduced sensory stimulation of pups that partly impairs the release of growth hormone (GH), oxytocin receptor levels, and ornithine decarboxylase (ODC), thus affecting the pups' 
brain development, mother-infant bonds, and the maternal response motivation in UG F1 sensitized virgins [23] [29] [30] [31]. During adulthood, UG F1 females expressed a disorganizing lower frequency values in most of the maternal behavior components, and prolonged latencies of sniffing, retrieval and handling shavings compared with CG F1 females, which may result in a negative social environment prone to inducing cognitive and/or brain disorders in later generations [1] [18] [32].

Together, our findings indicate that chronically exposing UG virgin female adult rats to a fresh set of pups induced the expression of disrupted and deficient maternal behavior components and a low interest in caring for the progeny, thus affecting the mother-infant bond recognition and the long-term physical and social development of the progeny. However, further studies using various periods of female sensitization, exposure to pups with different lactating ages, sensory stimulation to ameliorate the noxious foster dam-litter interactions, evaluate maternal sensitization with neurophysiological or neurochemical approaches are necessary for a better understanding of the mechanisms underlying the sensitization in early underfed rats.

In conclusion, perinatal undernutrition severely disrupted the expression of major maternal frequency components with fewer effects on the latencies of maternal response measurements when compared with F1 control virgin females. These alterations possibly hinder the quality of foster dam-infant interactions in F1 virgins, creating a deficient sensorial home environment that promotes long-term cognitive disorders. Current findings suggested that perinatal undernutrition interfered the functional organization of a core neuronal circuitry underlying the foster dam-litter interactions of UG F1 sensitized adult virgins that may influence the young social development.

\section{Acknowledgements}

This paper is partly supported by DGAPA/UNAM, IN200317. We thank Jessica González Norris for editorial assistance, and Serafín N. for her assistance with the data analysis.

\section{Conflicts of Interest}

The authors declare no conflicts of interest regarding the publication of this paper.

\section{References}

[1] Salcedo, C., Torrero, C., Regalado, M., Rubio, L. and Salas, M. (2018) Effects of Preand Neonatal Undernutrition on the Kyphotic Response and c-Fos Activity in the Caudal Periaqueductal Gray of Primiparous Lactating Wistar Rats. Physiology and Behavior, 185, 87-94. https://doi.org/10.1016/j.physbeh.2017.12.020

[2] Ayala-Moreno, R., Racotta, R., Anguiano, B., Aceves, C. and Quevedo, L. (2013) Perinatal Undernutrition Programmes Thyroid Function in the Adult Rat Offspring. British Journal of Nutrition, 110, 2207-2215. https://doi.org/10.1017/S0007114513001736 
[3] Murmu, M.S., Salomon, S., Biala, Y., Weinstock, M., Braun, K. and Bock, J. (2006) Changes of Spine Density and Dendritic Complexity in the Prefrontal Cortex in Offspring of Mothers Exposed to Stress during Pregnancy. European Journal of Neuroscience, 24, 1477-1487. https://doi.org/10.1111/j.1460-9568.2006.05024.x

[4] Numan, M. and Insel, T.R. (2003) Hormonal and Nonhormonal Basis of Maternal Behavior. In: The Neurobiology of Parental Behavior, Springer, New York, 8-41.

[5] Fleming, A.S. and Rosenblatt, J.S. (1974) Maternal Behavior in the Virgin and Lactating Rat. Journal of Comparative and Physiological Psychology, 6, 957-972. https://doi.org/10.1037/h0036414

[6] Seip, K.M. and Morrell, J.I. (2008) Exposure to Pups Influences the Strength of Maternal Motivation in Virgin Female Rats. Physiology and Behavior, 95, 599-608. https://doi.org/10.1016/j.physbeh.2008.09.003

[7] King, J.C. (2003) The Risk of Maternal Nutritional Depletion and Poor Outcomes Increases in Early or Closely Spaced Pregnancies. Journal of Nutrition, 133, 1732S-1736S. https://doi.org/10.1093/jn/133.5.1732S

[8] Lumey, L.H. (1998) Reproductive Outcomes in Women Prenatally Exposed to Undernutrition: A Review of Findings from the Dutch Famine Birth Cohort. Proceedings of the Nutrition Society, 57, 129-135. https://doi.org/10.1079/PNS19980019

[9] NCR National Research Council (2003) Guidelines for the Care and Use of Mammals. In: National Research Council of the National Academies (Ed.) Neuroscience and Behavioral Research, National Academies, Washington, 209.

[10] Lynch, A. (1976) Postnatal Undernutrition: An Alternative Method. Developmental Psychobiology, 9, 39-48. https://doi.org/10.1002/dev.420090107

[11] Altman, J. and Bayer, S.A. (1995) Atlas of Prenatal Rat Brain Development. CRC Press, Boca Raton.

[12] Belkacemi, L., Nelson, D.M., Desai, M. and Ross, M.G. (2010) Maternal Undernutrition Influences Placental-Fetal Development. Biology of Reproduction, 83, 325-331. https://doi.org/10.1095/biolreprod.110.084517

[13] Wu, G., Bazer, F.W., Cudd, T.A., Meininger, C.J. and Spencer, T.E. (2004) Maternal Nutrition and Fetal Development. Journal of Nutrition, 134, 2169-2172. https://doi.org/10.1093/jn/134.9.2169

[14] Lee, M.H.S. and Williams, D.I.I. (1974) Changes in Licking Behaviour of Rat Mother Following Handling of Young. Animal Behaviour, 22, 679-681. https://doi.org/10.1016/S0003-3472(74)80016-3

[15] Lopez-Jimenez, D., Torrero, C., Regalado, M. and Salas, M. (2013) Effects of Perinatal Undernutrition and Massage Stimulation upon the Ambiguus Nucleus in the Rat Prior to Weaning. Journal of Behavioral and Brain Science, 3, 200-209. https://doi.org/10.4236/jbbs.2013.32021

[16] Šefčíková, Z. and Mozeš, Š (2002) Effect of Early Nutritional Experience on the Feeding Behaviour of Adult Female Rats. Veterinary Medicine (Praha), 47, 315-322. https://doi.org/10.17221/5841-VETMED

[17] Frias, C., Torrero, C., Regalado, M. and Salas, M. (2006) Organization of Olfactory Glomeruli in Neonatally Undernourished Rats. Nutritional Neuroscience, 9, 49-55. https://doi.org/10.1080/10284150500506042

[18] Tonkiss, J., Galler, J.R., Shukitt-Hale, B. and Rocco, F.J. (1991) Prenatal Protein Malnutrition Impairs Visual Discrimination Learning in Adult Rats. Psychobiology, 19, 247-250.

[19] Riul, T.R., Carvalho, A.F., Almeida, P.S., De-Oliveira, L.M. and Almeida, S.S. (1999) 
Ethological Analysis of Mother-Pup Interactions and Other Behavioral Reactions in Rats: Effects of Malnutrition and Tactile Stimulation of the Pups. Brazilian Journal of Medical and Biological Research, 32, 975-983.

https://doi.org/10.1590/S0100-879X1999000800007

[20] Bousalham, R., Benazzouz, B., Hessni, A.E.L., Ouichou, A. and Mesfioui, A. (2013) Maternal Separation Affects Mothers' Affective and Reproductive Behaviors as Well as Second Offspring's Emotionality. Journal of Behavioral and Brain Science, 3, 409-414. https://doi.org/10.4236/jbbs.2013.35042

[21] Ortiz-Valladares, M., Torrero, C., Regalado, M. and Salas, M. (2018) Late-Emerging Effects of Perinatal Undernutrition in Neuronal Limbic Structures Underlying the Maternal Response in the Rat. Brain Research, 1700, 31-40. https://doi.org/10.1016/j.brainres.2018.06.033

[22] Fleming, A. and Walsh, C. (1994) Neuropsychology of Maternal Behavior in the Rat: c-fos Expression during Mother-Litter Interactions. Psychoneuroendocrinology, 19, 429-443. https://doi.org/10.1016/0306-4530(94)90030-2

[23] Smart, J.L. (1976) Maternal Behaviour of Undernourished Mother Rats toward Well Fed and Underfed Young. Physiology \& Behavior, 16, 147-149.

https://doi.org/10.1016/0031-9384(76)90298-5

[24] Tonkiss, J., Bonnie, K.E., Hudson, J.L., Shultz, P.L., Duran, P. and Galler, J.R. (2003) Ultrasonic Call Characteristics of Rat Pups Are Altered Following Prenatal Malnutrition. Developmental Psychobiology, 43, 90-101. https://doi.org/10.1002/dev.10124

[25] Nagasawa, M., Okabe, S., Mogi, K. and Kikusui, T. (2012) Oxytocin and Mutual Communication in Mother-Infant Bonding. Frontiers in Human Neuroscience, 6, 31. https://doi.org/10.3389/fnhum.2012.00031

[26] Pedersen, C.A., Johns, J.M., Musiol, I., Perez-Delgado, M., Ayers, G., Faggin, B. and Caldwell, J. (1995) Interfering with Somatosensory Stimulation from Pups Sensitizes Experienced, Postpartum Rat Mothers to Oxytocin Antagonist Inhibition of Maternal Behavior. Behavioral Neuroscience, 109, 980-990. https://doi.org/10.1037/0735-7044.109.5.980

[27] Weinstock, M. (2001) Alterations Induced by Gestational Stress in Brain Morphology and Behaviour of the Offspring. Progress in Neurobiology, 65, 427-451. https://doi.org/10.1016/S0301-0082(01)00018-1

[28] Pryce, C.R., Bettschen, D. and Feldon, J. (2001) Comparison of the Effects of Early Handling and Early Deprivation on Maternal Care in the Rat. Developmental Psychobiology, 38, 239-251. https://doi.org/10.1002/dev.1018

[29] DeVries, A.C. (2002) Interaction among Social Environment, the Hypothalamic-Pituitary-Adrenal Axis, and Behavior. Hormones and Behavior, 41, 405-413. https://doi.org/10.1006/hbeh.2002.1780

[30] Evoniuk, G.E., Kuhn, C.M. and Schanberg, S.M. (1979) The Effect of Tactile Stimulation on Serum Growth Hormone and Tissue Ornithine Decarboxylase Activity during Maternal Deprivation in Rat Pups. Communication in Psychopharmacology, 3, 363-370.

[31] Francis, D.D., Champagne, F.C. and Meaney, M.J. (2000) Variations in Maternal Behaviour Are Associated with Differences in Oxytocin Receptor Levels in the rat. Journal of Neuroendocrinology, 12, 1145-1148. https://doi.org/10.1046/j.1365-2826.2000.00599.x

[32] Salas, M., Torrero, C., Regalado, M. and Perez, E. (2002) Retrieving of Pups by Neonatally Stressed Mothers. Nutritional Neuroscience, 5, 399-405. https://doi.org/10.1080/1028415021000055943 